\title{
PENGARUH LITERASI KEUANGAN DAN FINANCIAL TECHNOLOGY TERHADAP LABA UMKM (STUDI EMPIRIS UMKM DI KOTA SURABAYA)
}

\section{Adenna Hendy Cassie Putri, Sri Hastuti}

Universitas Pembangunan Nasional (UPN) Veteran Jawa Timur, Indonesia.

Email: adennahendy@gmail.com, sri.hastuti18@gmail.com

\begin{tabular}{l}
\hline INFO ARTIKEL \\
\hline Diterima \\
12 Oktober 2021 \\
Direvisi \\
19 Oktober 2021 \\
Disetujui \\
28 November 2021 \\
\hline
\end{tabular}

Kata Kunci:

Literasi Keuangan, Financial

Technology, Laba

\section{ABSTRAK}

Laba merupakan salah satu faktor yang menentukan keberhasilan suatu usaha. Di era modernisasi seperti sekarang, Literasi Keuangan dan Financial Technology menjadi salah satu faktor yang membantu pelaku usaha untuk memperoleh laba yang diinginkan. Namun, masih $20 \%$ saja yang memahami tentang Literasi Keuangan. Selain itu, sebagian besar pelaku usaha juga belum menerapkan Financial Technology yang sebenarnya dapat membantu transaksi jual beli secara cepat dan mudah. Penelitian ini bertujuan untuk menguji secara empiris pengaruh Literasi Keuangan dan pengaruh Financial Technology terhadap Laba UMKM. Penelitian ini menggunakan pendekatan kuantitatif, dengan pengumpulan data menggunakan instrumen kuesioner. Penelitian ini dilakukan pada UMKM di Kota Surabaya dengan jumlah pemilik usaha yang berjumlah 237 orang. Teknik pengambilan sampel penelitian ini menggunakan teknik simple random sampling. Teknik simple random sampling merupakan teknik pengambilan sampel dari suatu populasi yang dilakukan secara acak tanpa memperhatikan strata dari populasi, dengan metode tersebut maka sampel yang digunakan dalam penelitian ini adalah 99 orang. Teknik analisis data penelitian ini menggunakan Partial Least Squares (PLS) dengan software SmartPLS 3.0. Hasil penelitian menunjukkan bahwa (1) Literasi Keuangan berpengaruh terhadap Laba UMKM, dan (2) Financial Technology tidak berpengaruh terhadap Laba UMKM.

\footnotetext{
ABSTRACT

Profit is one of the factors that determine the success of a bussiness. In the Modernization era as it is now Financial Literacy and Financial Technology is one of the factors that helps bussiness to obtain the desired profit. However oli 20\% to understand Financial Literacy in Indonesian. And then, The bussinessman have not yet implemented Financial Technology which can actually help to buying and selling transaction to easy this research to examine empirically the influence of Financial Literacy and Financial Technology on the UMKM profit in Surabaya City. This research uses a quantitative apporch, with collecting research data by using a quantionner instruments. This research was conducted UMKM in Surabaya City with population in this research is one of the bussinessman at UMKM in Surabaya City which amounted to 237 units UMKM. Sampling technique in this research is simple random sampling. Simple Random Sampling Technique is a sampling technique from a population that is done randomly regardless of the strata of the population, with this method the sample used in this research is 99
}

Keywords: Financial 


\begin{tabular}{ll}
\hline Literacy, & people's Data analysis technique in this research using Partial Least \\
Financial & Square (PLS) by using software SmartPLS 3.0. The result of the shows \\
Technology, & that (1) Financial Literacy has influence on the Profit UMKM (2) \\
Profit & Financial Technology has not influence on the Profit UMKM. \\
\hline
\end{tabular}

\section{Pendahuluan}

Literasi Keuangan (Financial Literacy) telah menjadi perhatian khusus di berbagai negara, khususnya negara-negara ASEAN. Hal tersebut dikarenakan setiap negara ingin membentuk suatu pola pikir masyarakatnya untuk memiliki pola pikir keuangan yang berkualitas serta baik dalam mengelola keuangannya (Agusta, 2016). Dengan begitu diharapkan akan berdampak positif bagi perkembangan perekonomian Indonesia. Berdasarkan hasil survey Bank Dunia yang menyatakan bahwa tingkat Literasi Keuangan di Indonesia hanya 20\% saja. Angka tersebut lebih rendah apabila dibandingkan dengan negara-negara di ASEAN lainnya. Contohnya seperti negara Filipina 27\%, Malaysia 66\%, Thailand $73 \%$, dan Singapura sebesar 98\% (Source : Bank Pundi). Serta beberapa negara pun telah melakukan penelitian mengenai Literasi Keuangan (Indonesia, 2015). Oleh karena itu pada tahun 2013, Indonesia meluncurkan 3 strategi untuk meningkatkan Literasi Keuangan di Indonesia yaitu : Edukasi dan kampanye Nasional Literasi Keuangan, Penguatan infrastruktur Literasi Keuangan dan pengembangan produk dan jasa keuangan (Sakina Rakhma Diah Setiawan, 2013).

Menurut (Agusta, 2016) menyatakan bahwa Literasi Keuangan mencangkup konsep yang dimulai dari kesadaran dan pemahaman tentang produk-produk keuangan. Institusi keuangan dan konsep mengenai keterampilan keuangan seperti kemampuan untuk menghitung bunga majemuk, serta kemampuan keuangan yang lebih umum seperti : perencanaan, pengelolaan, dan pengalokasian keuangan. Literasi Keuangan secara sederhana pun juga diartikan sebagai kemampuan seserorang dalam mengelola keuangannya dan melakukan perencanaan keuangannya. Literasi Keuangan juga berpengaruh pada pelaku usaha. Karena pemahaman bukan hanya ditujukan pada masyarakat yang bekerja di perkantoran atau di pemerintahan saja, namun bagi seluruh masyarakat Indonesia harus paham benar mengenai Literasi Keuangan, salah satunya adalah pelaku usaha UMKM (Tambunan, 2012).

Usaha mikro kecil menengah (UMKM) memiliki peran yang sangat andil dalam perekonomian di Indonesia, dalam upaya peningkatan pertumbuhan ekonomi dalam pembangunan perekonomian di Indonesia, serta membuka lapangan kerja baru bagi masyarakat Indonesia. Dengan peningkatan dan berkembangnya UMKM di Indonesia diharapkan dapat membuka lapangan pekerjaan baru bagi masyarakat Indonesia untuk mengurangi kemiskinan dan pengangguran serta membantu meningkatkan pertumbuhan Produk Domestik Bruto (PDB) (Rifa'i, 2013). Karena semakin banyaknya UMKM yang terus bermunculan membuat persaingan antar UMKM semakin ketat. Terlebih lagi setelah diberlakukannya Masyarakat Ekonomi ASEAN (MEA), yang menuntut pelaku usaha UMKM untuk terus memberikan inovasi-inovasi baru agar dapat memenuhi kebutuhan pasar serta membuat negara Indonesia sebagai market leader di negara sendiri maupun di ASEAN (Usman, 2016).

Sektor keuangan merupakan sektor yang penting bagi pertumbuhan ekonomi di Indonesia, Hal ini yang mengakibatkan sektor keuangan terus menerus melakukan perkembangan sesuai dengan kebutuhan masyarakat. Baru-baru ini muncul sebuah inovasi teknologi dalam sektor keuangan 
yakni Financial Technology. Lembaga Asosiasi Fintech Indonesia (AFI) menjadikan fintech sebagai sorotan yang dimulai sejak tahun 2015, asosiasi ini memiliki tujuan menyediakan sarana dan prasarana untuk menyediakan partner bisnis yang dapat dipercaya dan bekerjasama untuk membangun perusahaan-perusahaan fintech di Indonesia (Dorfleitner, 2019). Financial Technologi atau yang biasa disebut dengan fintech merupakan terobosan terbaru dalam bidang keuangan di era revolusi industri

4.0. Menurut The National Digital Research Finansial. Fintech berasal dari istilah financial technology atau teknologi finansial. Beberapa dampak positif yang akan timbul apabila menggunakan fintech adalah kemudahan dalam hal bertransaksi jual beli, Usaha Mikro Kecil Menengah (UMKM) memiliki peran yang cukup besar untuk meningkatkan pertumbuhan ekonomi di Indonesia. Dan munculnya inovasi baru seperti Financial Technology memberikan udara segar bagi pelaku UMKM. Financial Technology secara tidak langsung membantu pelaku usaha UMKM untuk mendapatkan akses lebih mudah melakukan produk keuangan serta meningkatkan Literasi Keuangan. Pelaku bisnis UMKM dapat memanfaatkan Financial Technology sebagai pembiayaan modal usaha dan mampu meningkatkan laba pelaku usaha UMKM. Serta dapat digunakan sebagai layanan pembayaran digital serta sebagai pengatur keuangan. Dan kehadiran Financial
Technology juga hadir di saat teknologi semakin canggih (Subramanyam, 2014).

Berdasarkan latar belakang tersebut, maka masalah dalam penelitian ini dapat diidentifikasi sebagai berikut : (1) Apakah Literasi Keuangan berpengaruh terhadap Laba UMKM ? (2) Apakah Financial Technology berpengaruh terhadap Laba UMKM ?.

\section{Metode Penelitian}

Jenis penelitian kuantitatif (Suliyanto \& MM, 2017) Objek penelitian yang ditetapkan dalam penelitian ini disesuaikan dengan permasalahan yang akan diteliti yaitu seorang pemilik usaha pada UMKM di Kota Surabaya. Populasi yang digunakan dalam penelitian ini adalah satu orang pemilik usaha UMKM di Kota Surabaya dengan jumlah 237 pelaku usaha UMKM. Dan untuk menghitung jumlah sample dalam penelitian ini ditentukan dengan menggunakan rumus Slovin dengan jumlah 70 responden.

Instrumen penelitian yang digunakan dalam penelitian ini berupa angket atau kuesioner yang dibuat oleh peneliti. Jenis data yang digunakan dalam penelitian ini adalah data primer yang diperoleh secara langsung dari responden.

Penelitian ini merupakan penelitian yang menggunakan pendekatan kuantitatif dengan metode analisis data SEM berbasis Partial Least Square (PLS) dengan pengujian hipotesis menggunakan (Khoi \& Ngan, 2019). 


\section{Hasil dan Pembahasan}

A. Hasil Penelitian

1. Evaluasi Model Pengukuran (Outer Model)

Tabel 1

Convergent Validity (Tahap 1)

\begin{tabular}{lccc}
\hline & $\begin{array}{c}\text { Literasi } \\
\text { Keuangan }\end{array}$ & $\begin{array}{c}\text { Financial } \\
\text { Technology }\end{array}$ & Laba \\
\hline $\mathrm{X} 1.1$ & 0.855 & & \\
\hline $\mathrm{X} 1.2$ & 0.416 & & \\
\hline $\mathrm{X} 1.3$ & 0.875 & & \\
\hline $\mathrm{X} 1.4$ & 0.458 & & \\
\hline $\mathrm{X} 2.1$ & & 0.783 & \\
\hline $\mathrm{X} 2.2$ & & 0,420 & \\
\hline $\mathrm{X} 2.3$ & & 0.751 & \\
\hline $\mathrm{X} 2.4$ & & 0.721 & \\
\hline $\mathrm{X} 2.5$ & & 0.757 & \\
\hline $\mathrm{Y} 1$ & & & 0.286 \\
\hline $\mathrm{Y} 2$ & & 0.863 \\
\hline $\mathrm{Y} 3$ & & & 0.888 \\
\hline $\mathrm{Y} 4$ & & 0.593 \\
\hline $\mathrm{Y} 5$ & & 0.801 \\
\hline
\end{tabular}

Berdasarkan tabel 1 dapat dilihat bahwa hasil outer loading menunjukan nilai loading factor untuk 5 (Lima) indikator yang masih dibawah 0.70 yaitu : X1.2, $\mathrm{X} 1.4, \mathrm{X} 2.2, \mathrm{Y} 1$ dan $\mathrm{Y} 4$ yang artinya indikator-indikator tersebut tidak valid sehingga harus dikeluarkan dari model dan dilakukan pengujian tahapan ke 2.

Tabel 2

Convergent Validity (Tahap 2)

\begin{tabular}{lccc}
\hline & Literasi Keuangan & Financial Technology & Laba \\
\hline $\mathrm{X} 1.1$ & 0.900 & & \\
\hline $\mathrm{X} 1.3$ & 0.889 & & \\
\hline $\mathrm{X} 2.1$ & & 0.731 & \\
\hline $\mathrm{X} 2.3$ & 0.788 & \\
\hline $\mathrm{X} 2.4$ & 0.752 & \\
\hline $\mathrm{X} 2.5$ & 0.802 & 0.861 \\
$\mathrm{Y} 2$ & & 0.887 \\
\hline $\mathrm{Y} 3$ & & 0.837 \\
\hline Y5 & & \\
\hline
\end{tabular}

Berdasarkan tabel 2 hasil pengujian di tahapan kedua menunjukan bahwa semua nilai loadings factor untuk setiap indikator menunjukan nilai lebih dari 0.70 sehingga dapat disimpulkan bahwa indikator tersebut convergent validity. 
Tabel 3

Discriminant Validity

\begin{tabular}{lccc}
\hline & Literasi Keuangan & Financial Technology & Laba \\
\hline X1.1 & 0,900 & 0.608 & 0.837 \\
\hline X1.3 & 0,889 & 0.639 & 0,800 \\
\hline X2.1 & 0,560 & 0.731 & 0.597 \\
\hline X2.3 & 0.575 & 0.788 & 0.502 \\
\hline X2.4 & 0.398 & 0.752 & 0.355 \\
\hline X2.5 & 0.559 & 0.802 & 0,490 \\
\hline Y2 & 0.641 & 0,520 & 0.861 \\
\hline Y3 & 0.779 & 0.544 & 0.887 \\
\hline Y5 & 0,900 & 0.608 & 0,837 \\
\hline
\end{tabular}

Berdasarkan tabel 3 dapat diketahui bahwa masing-masing indikator memiliki nilai cross loadings $>0,70$, sehingga indikator tersebut dapat dikatakan valid 2. Uji Reliabilitas untuk mengukur variable lain yang bersesuaian.

Tabel 4

Construct Reliability and Validity

\begin{tabular}{lcccc}
\hline & $\begin{array}{l}\text { Crobach's } \\
\text { Alpha }\end{array}$ & Rho_A & $\begin{array}{l}\text { Composite } \\
\text { Reliability }\end{array}$ & $\begin{array}{l}\text { Average Variance } \\
\text { Extracted } \\
\text { (AVE) }\end{array}$ \\
\hline Laba & & & & 0.743 \\
\hline Literasi Keuangan & 0.829 & 0.842 & 0.897 & 0,800 \\
\hline Financial Technology & 0.751 & 0.752 & 0.889 & 0.591 \\
\hline
\end{tabular}

Berdasarkan Tabel 4 menunjukan nilai AVE yang dihasilkan dari semua konstruk sebesar $>0,05$ yang berarti memenuhi syarat reliabilitas. Hasil output
Composite Reliability and Crobach Alpha nilainya juga $>0.70$ yang memiliki arti semua kontruk reliabilitasnya baik.

3. Evaluasi Model Struktural

Tabel 5

R-Square

\begin{tabular}{lcc}
\hline & \multicolumn{2}{c}{ R Square Adjusted } \\
\hline Laba & $\underline{0.836}$ & $\underline{0.835}$ \\
\hline
\end{tabular}

Berdasarkan tabel 5 menunjukan oleh variable lain diluar variable yang diteliti. bahwa Laba memiliki nilai 0,0836 atau $83,6 \%$ untuk sisanya $16,4 \%$ dijelaskan 
Tabel 6

Path Coefficients

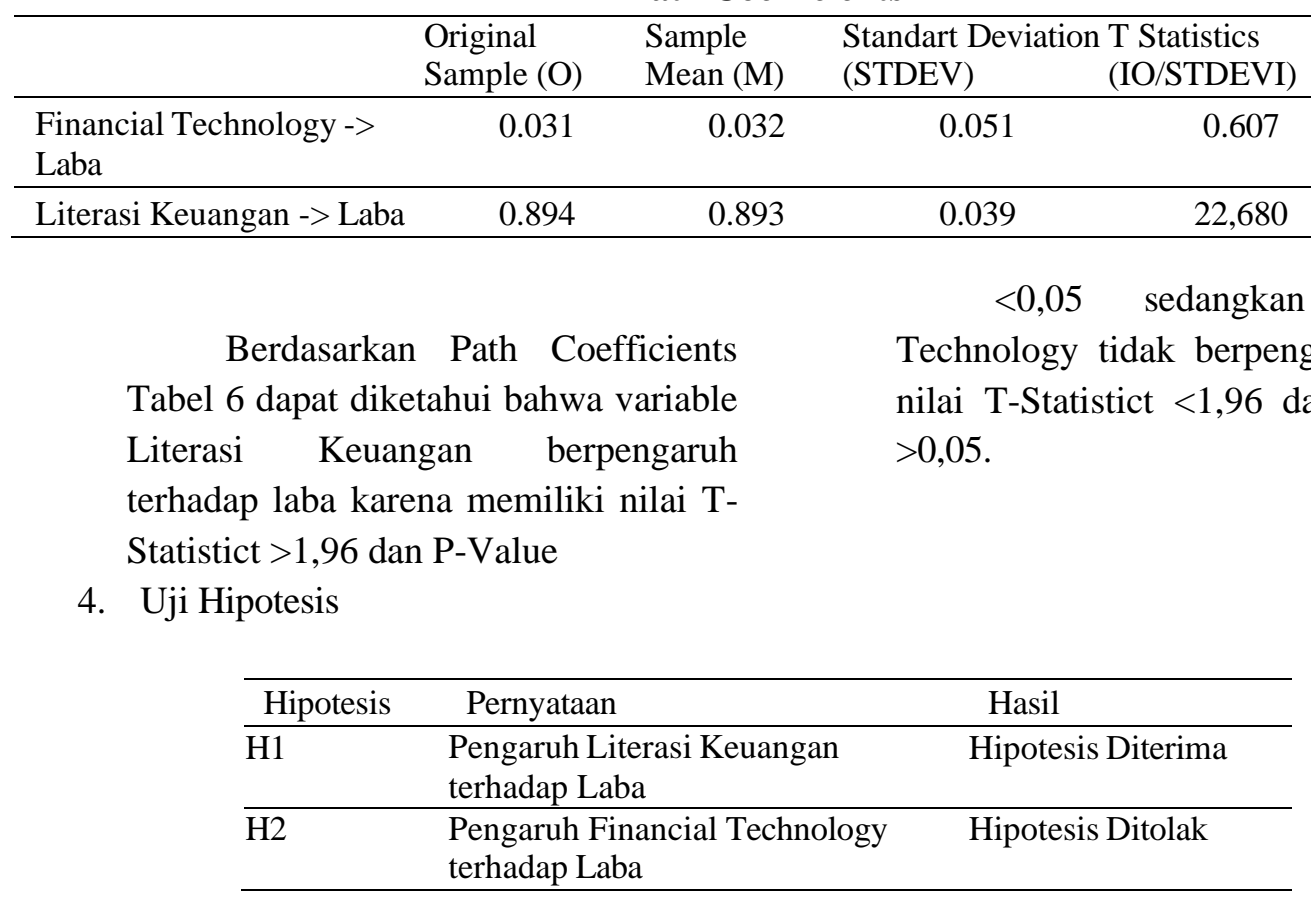

a.Pengujian Hipotesis $(\mathrm{H} 1=$ Literasi

Keuangan berpengaruh terhadap Laba UMKM di Surabaya) Hipotesis pertama menyatakan bahwa Literasi Keuangan berpengaruh terhadap Laba UMKM di Surabaya. Berdasarkan nilai path coefficient, nilai koefisien parameter original sebesar 0,894 , nilai tstatistik sebesar 22.680 yang memiliki arti $(>1,96)$, dan nilai $\mathrm{p}$ Values sebesar 0,000 yang memiliki $(<0,05)$. Dengan demikian variabel Financial Technology dinyatakan berpengaruh signifikan terhadap Laba UMKM di Surabaya.

b. Pengujian Hipotesis $(\mathrm{H} 2=$ Financial Technology tidak berpengaruh terhadap Laba UMKM di Surabaya. Hipotesis kedua menyatakan bahwa Financial Technology tidak berpengaruh terhadap Laba UMKM. Berdasarkan nilai path coefficient, nilai koefisien parameter original sebesar 0,031, nilai t-statistik sebesar 0,607 yang memiliki arti $(<1,96)$, dan nilai $\mathrm{p}$-Values sebesar
0,544 yang memiliki arti $(>0,05)$. Dengan demikian variabel Financial Technology dinyatakan tidak berpengaruh signifikan terhadap Laba UMKM di Surabaya.

\section{B. Pembahasan}

1. Pengaruh Literasi Keuangan terhadap Laba

Berdasarkan hasil pengujian outer dan inner model sebagaimana yang ditampilkan pada tabel 4 dimana pada uji hubungan antar konstruk dapat disimpulkan bahwa Literasi Keuangan berpengaruh signifikan terhadap Laba. Diterimanya Hipotesis 1, memberikan makna bahwa semakin tinggi tingkat pemahaman mengenai Literasi Keuangan seseorang maka akan semakin tinggi Laba/Keuntungan yang akan diperolehnya. Hasil dari analisis tersebut secara konsisten sama dengan penelitian terdahulu yang dilakukan oleh Anggraeni (2015) dan Saputri (2019) namun, bertentangan dengan penelitian oleh Rubianingrum dan Wijayanka (2018). 
2. Pengaruh Financial Technology terhadap Laba

Berdasarkan hasil pengujian outer dan inner model sebagaimana yang ditampilkan pada tabel 4 dimana pada uji hubungan antar konstruk dapat disimpulkan bahwa Financial Technology tidak berpengaruh terhadap Laba. Ditolaknya Hipotesis 2, memberikan makna bahwa Financial Technology tidak secara langsung berpengaruh terhadap Laba. Hal tersebut disebabkan oleh, masih banyaknya pelaku usaha UMKM di Surabaya yang belum menerapkan Financial technology untuk usaha mereka. Dan mereka merasa bahwa memperoleh Laba/Keuntungan hanya bisa didapat dengan melakukan transaksi secara langsung atau pembayaran tunai. ( Riza, Pelaku usaha di Sentra UMKM Surabaya). Hasil analisis tersebut bertentangan dengan penelitian dari Firdaus (2019) dan Prastiska (2019 yang menyatakan berpengaruh/positif.

\section{Kesimpulan}

Berdasarkan hasil pengujian dan pembahasan peneltiian yang berjudul "Pengaruh Literasi Keuangan dan Financial Technology terhadap Laba UMKM (Studi empiris UMKM di Kota Surabaya)", maka dapat disimpulkan sebagai berikut (1) Literasi Keuangan berpengaruh terhadap Laba UMKM, (2) Financial Technology tidak berpengaruh terhadap Laba UMKM.

\section{Bibliografi}

Agusta, A. (2016). Analisis deskriptif tingkat literasi keuangan pada UMKM di pasar Koga Bandar Lampung.Google Scholar

Dorfleitner, H. (2019). Schmitt, \& Weber.(2017). Retrieved Maret Minggu. Google Scholar
Indonesia, K. K. R. (2015). Perkembangan Perekonomian Terkini. Jakarta. $H, 1$. Google Scholar

Khoi, B. H., \& Ngan, N. T. (2019). Factors impacting to smart city in Vietnam with smartpls 3.0 software application. IIOAB, 1O(2), 1-8. Google Scholar

Rifa'i, B. (2013). Efektivitas Pemberdayaan Usaha Mikro Kecil dan Menengah (UMKM) Krupuk Ikan dalam Program Pengembangan Labsite Pemberdayaan Masyarakat Desa Kedung Rejo Kecamatan Jabon Kabupaten Sidoarjo. Sumber, 100(100), 2-59. Google Scholar

Sakina Rakhma Diah Setiawan. (2013). OJK Canangkan Tiga Pilar Literasi Keuangan. https://money.kompas.com/read/2013/1 1/18/1446545/OJK.Canangkan.Tiga.Pila r.Literasi.Keuangan

Subramanyam, K. R. (2014). Financial statement analysis. McGraw-Hill Education. Google Scholar

Suliyanto, S. E., \& MM, S. (2017). Metode Penelitian Kuantitatif. Google Scholar

Tambunan, T. (2012). UMKM Indonesia. BUKU DOSEN-2014. Google Scholar

Usman, F. (2016). Masyarakat Ekonomi ASEAN (MEA) dan daya saing investasi Indonesia. Jurnal Lingkar Widyaiswara, 3(1), 33-36. Google Scholar 


\section{Copyright holder :}

Adenna Hendy Cassie Putri, Sri Hastuti (2021).

First publication right :

Action Research Literate

This article is licensed under:

(c) (i) (? 